\title{
Smoking and normative influence among Egyptian youth: a review of the literature
}

\author{
C. Harbour ${ }^{1}$
}

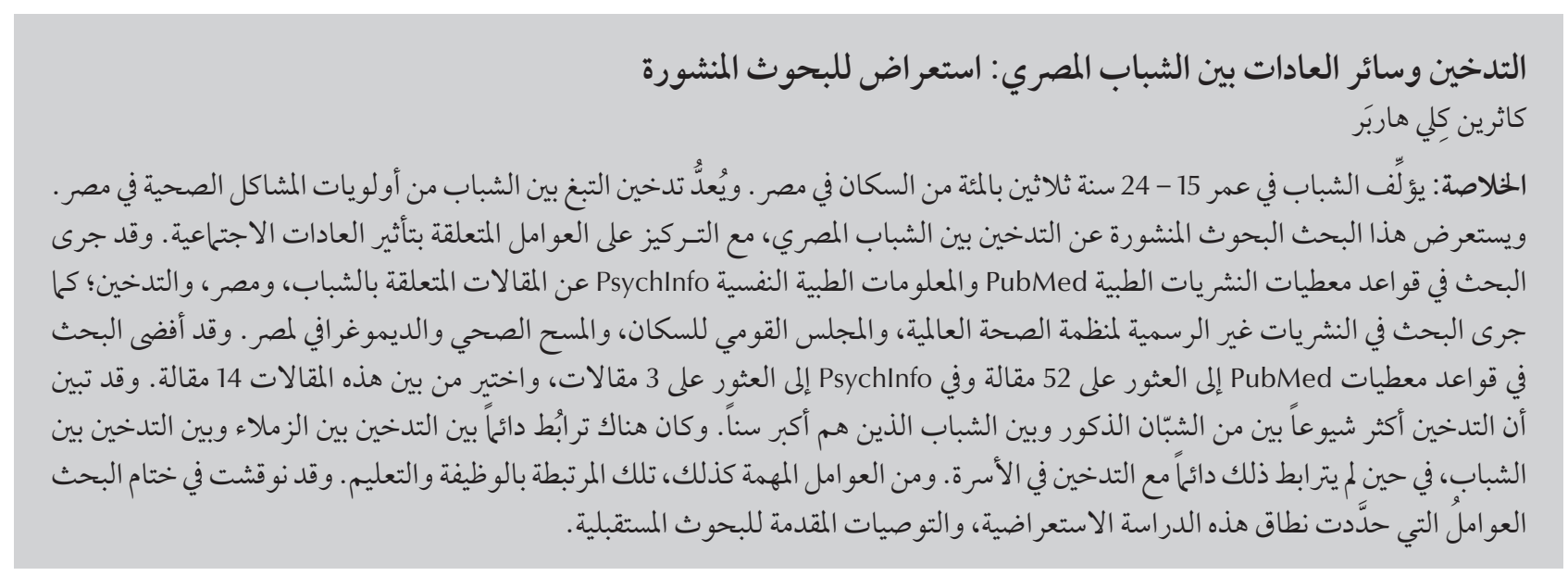

ABSTRACT Youth aged 15-24 years form 21\% of Egypt's population. Tobacco smoking among the young is a health priority in Egypt. This paper reviews the literature on smoking among Egyptian youth, focusing on factors related to social normative influences. The PubMed and Psyclnfo databases were searched for articles related to youth, Egypt and smoking; and grey literature from the World Health Organization, Population Council and the Egypt Demographic and Health Survey were also accessed. The PubMed and PsycInfo searches returned 52 and 3 publications respectively, of which 14 were retained. Smoking is more common among male youth and older youth. Peer smoking is consistently associated with youth smoking, but family smoking is not consistently associated. Employment and educational factors appear to be important. The limitations of the review and recommendations for future research are discussed.

Tabagisme et influence de la norme sociale chez les jeunes égyptiens : une synthèse de la littérature

RÉSUMÉ Les jeunes âgés de 15 à 24 ans représentent $21 \%$ de la population égyptienne. La consommation de tabac chez les jeunes est une question de santé publique prioritaire en Égypte. Le présent article analyse la littérature traitant du tabagisme chez les jeunes égyptiens, en se polarisant sur les facteurs liés aux influences de la norme sociale dans ce domaine. Les bases de données PubMed et Psyclnfo ont été utilisées pour rechercher des articles contenant des mots clés tels que les jeunes, l'Égypte et le tabagisme. La littérature grise provenant de l'Organisation mondiale de Santé, Population Council et l'Enquête démographique et de Santé en Égypte ont également été consultées. Les recherches dans PubMed et PsycInfo ont généré 52 et 3 publications respectivement, parmi lesquelles 14 ont été retenues. Le tabagisme est plus fréquent chez les jeunes de sexe masculin et dans les tranches d'âges plus avancés. Le tabagisme des pairs est associé de manière constante au tabagisme des jeunes, contrairement au tabagisme familial. Les facteurs concernant l'activité professionnelle et le niveau d'études semblent également importants. Les limites de la présente analyse et la rédaction de recommandations pour les prochaines recherches sont actuellement en discussion. 


\section{Introduction}

Youth aged 15-24 years are estimated to constitute $21 \%$ of Egypt's population and by 2025 , their population is projected to reach almost 18 million [1]. This "youth bulge" offers Egypt a "demographic giff" of a large number of working-age citizens with a relatively low number of older and younger nonworking people to support [2]. Consequently, tobacco smoking among youth is a serious health issue in Egypt. Egypt has reported the highest rate of tobacco use of all the countries of the Middle East and North Africa [3]. Although population growth is $2 \%$, the number of smokers in Egypt has increased by $8 \%-9 \%$ each year for the past 30 years, and tobacco advertisers have targeted youth in order to grow the tobacco industry $[4,5]$. The long-term health effects of smoking on Egypt's greatest human resource - its youth - and the future health care costs of a large population of smokers threaten to transform the demographic gift into a demographic burden.

Social norms are "group identitybased codes of conduct that are understood and disseminated through social interaction," and can encourage or discourage behaviours such as smoking [6]. Norms are an essential component of peer group identity [6]. Perceptions of norms and normative influences are important components of wellestablished theories of behaviour change and of communication, such as the Theory of Planned Behaviour and Social CognitiveTheory $[7,8]$.

\section{Objectives}

This article reviews the literature on Egyptian youth tobacco smoking so as to identify the attributes of youth that research has found to be associated with smoking behaviours and that may also be related to youth peer groups and social norms. Few studies have explicitly researched the relationships between social norms and smoking behaviours among youth in Egypt. However, many studies have described the prevalence and habits of youth smoking according to one or more demographic characteristics such as sex and age. Particularly among youth in school with friends of the same age, these demographic characteristics are likely to correspond to social networks and friendship groups and the concomitant social norms pertinent to these groups. This article first summarizes the relationships identified between the smoking behaviour of Egyptian youths and selected demographic characteristics, and then summarizes the relationships identified in research between youths' tobacco smoking behaviours and their household and peer social normative environments.

\section{Sources}

The literature selected for this review was identified through key word searches of the PubMed and PsycInfo databases. The searches were conducted in October 2009. PubMed is a service of the US National Institutes of Health and provides citations from the biomedical literature [9]. PsycInfo is a database service of the American Psychological Association, with citations from the psychological literature and the psychological aspects of related disciplines [10]. Additional "grey literature" resources from the World Health Organization (WHO), Population Council, and Egypt Demographic and Health Surveys (DHS) were also reviewed.

\section{Methods of selection}

The PubMed and PsycInfo databases were accessed using the search terms " (youth or adolesc*) AND Egypt AND (smok ${ }^{*}$ or tobacco)." When "norm*" was added to these search terms, no articles were returned on PubMed. The PubMed search returned 52 articles, of which 14 were retained. Articles excluded were those that were: published before 1997 (15 articles); primarily about waterpipe smoking (2 articles); research conducted on Egyptians living outside of Egypt (1 article); or reports discussing smoking status as an independent variable related to other health outcomes and not as the primary focus of the article (e.g. hepatitis C, abortion, and levels of cadmium and arsenic) (21 articles). The PsycInfo search returned 3 articles: 2 articles that were also returned in the PubMed search and 1 dissertation (by S. Islam) that appeared to report the same research as the 2 articles $[11,12]$. Other "grey literature" on Egyptian youth smoking was accessed from the Population Council, the WHO and the Egypt DHS websites.

\section{Compilation and interpretation of data}

\section{Smoking behaviours}

Several national studies and a number of local or regional research studies have looked at smoking among Egyptian youth. National studies include WHO's global youth tobacco survey (GYTS), conducted in 2001, 2004 and 2005; the Population Council's survey of young people in Egypt (SYPE), conducted in 2009; the Population Council's adolescence and social change in Egypt (ASCE) survey, conducted in 1998; and the Egypt DHS, which collected information on tobacco use in 2000, 2005 and $2008[2,13-17]$

The 2005 GYTS surveyed 4196 Egyptian students in the 2nd and 3rd level of preparatory school and the 1st level of secondary school and found that $13.6 \%$ of students had ever smoked cigarettes and $14.4 \%$ reported currently using a tobacco product [13]. The ASCE found that among a nationallyrepresentative sample of 9128 youth aged $10-19$ years, $5.5 \%$ were current smokers and $23.0 \%$ reported that their peers smoked [14]. 


\section{Sex and age}

Sex and age play important roles. Research consistently finds that smoking in Egypt is more prevalent among male youth than among female youth, and that smoking prevalence increases with age $[4,11,13,17-23]$. The 2005 GYTS found that $19.7 \%$ of males had ever used a tobacco product and $17.6 \%$ currently used tobacco, compared with $5.7 \%$ and $8.6 \%$ respectively among female students in the same grades [13]. The Population Council's 2009 SYPE found that $26 \%$ of male youth aged 15-29 years reported smoking, most of whom were aged 18-29 years [2]. The Council's earlier ASCE survey found that $11.2 \%$ of male adolescents reported smoking, compared with only $0.3 \%$ of females. The researchers suggest that these figures underestimate the actual percentage of youth smoking, since $42.2 \%$ of young men and $5.1 \%$ of young women reported that their peers smoked [14]. In the 2008 DHS, $0.3 \%$ of women aged $15-19$ reported smoking, although $56.2 \%$ said they lived with a smoker. Among men in the 2008 DHS, $18.9 \%$ of those aged $15-19$ years reported that they smoked and 50.9\% reported living with a smoker. As in the SYPE data, smoking was more prevalent among the older youth cohort: $43.2 \%$ of men aged 20-29 years reported smoking, while $41.9 \%$ said they lived with a smoker, and $0.6 \%$ of women 20-29 years reported smoking, while $54.2 \%$ reported living with a smoker [17].

Local and regional studies tell a similar story. A 2003 survey of 1930 high-school students (51\% male, 49\% female) aged 13-19 years in school grades 7,9, and 12 in Alexandria found that $25 \%$ of youth had ever-smoked, $12 \%$ had smoked in the previous 30 days and $6 \%$ were current smokers. These 3 smoking behaviours were more prevalent among males than females, and the differences were statistically significant. In that study $34 \%$ of males and $16 \%$ of females reported ever-smoking, 16\% of males and $7 \%$ of females reported having smoked in the previous 30 days, and $8 \%$ of males and $4 \%$ of females reported current smoking [11]. A study of 635 students in rural secondary schools in Qualyobia governorate in the Nile Delta region found that $11.5 \%$ of males and $0 \%$ of female students reported current smoking, defined as having smoked at least once in the 30 days preceding the survey; and $60 \%$ of males and $93 \%$ of females reported never smoking [19]. A study of 600 University of Alexandria hostel residents found that $17.5 \%$ of males ( 46 out of 263 ) and $0 \%$ of females (0 out of 337) were current smokers [24]. In a survey of 559 University of Cairo students aged $15-27$ years, $50.9 \%$ of males had ever smoked and 22.0\% were current smokers, compared with $11.9 \%$ of females who had ever smoked and $1.7 \%$ of females who currently smoked [4]. A similar sex disparity was reported in a survey of a convenience sample of 302 students aged 14-18 years from Cairo, Giza and Qualyobia: the overall prevalence of current smoking was $8.3 \%$, but smoking was more prevalent among male students (13.2\%) than among females (3.3\%) [23].

The lower rates of smoking noted among women may reflect social traditions and women's lesser economic resources compared to men's [18]. Gadalla et al. also emphasized the link between sex roles and smoking, noting that "smoking among females is not socially accepted in Egypt, especially in rural communities, where they consider it a male behaviour" [19]. Other researchers suggest that young women may underreport smoking behaviour in surveys because of a taboo against female smoking, so the actual prevalence among young women may be higher than the available data suggest $[4,11]$. Based on their 2003 survey of Alexandria high-school students, Islam and Johnson performed a mediation analysis of adolescent smoking behaviour and exposure to Western media, assessed through an index developed from responses to 6 self-reported questions, including
"I watch Western movies and/or TV shows," "I read Western magazines and newspapers," and "How much do you enjoy listening to Western music?" They found that exposure to Western media was associated with an increased risk of 30-day smoking behaviour among Egyptian males but not females. The differential influence was due only to the effect that the Western media had on increasing adolescent males' positive beliefs about smoking. The authors suggest that the differential influence may relate to "gender-differentiated cultural norms associated with Islamic Arab patriarchal societies, such as Egypt", where smoking is socially acceptable for adult males but not for females, and the greater prevalence of male movie stars than female movie stars shown smoking in Western films [11].

Young men may initiate smoking earlier than young women, and youth seem to smoke less heavily than adults. In a community-based survey of 2120 people aged 15 years and over in $\mathrm{Al}$ exandria, $48.5 \%$ (586 of 1162) of the men were current smokers and their average age of initiation was 18.1 years. Among women, 1.5\% (14 of 958) were current smokers, and their average age of initiation was 22.6 years [18]. Younger smokers may smoke less frequently than older smokers. As part of the Community Trial for Prevention of Environmental Tobacco Smoke, 7657 adults aged 18 and over in 6 villages in 2 districts in Qualyobia governorate were surveyed. The researchers found that 1401 males (37.6\%) and 5 females $(0.1 \%)$ were smokers, and that those who smoked less than daily tended to be younger. Of those respondents 18-24 years who were smokers, about 10\% smoked less than once a day compared with only $4 \%$ of those aged $25-44$ years and $2 \%$ of those over 45 years who reported smoking less than once a day and not more frequently [25]. ASCE also found that heavy smoking was less common than was light smoking. Among those young men who reported that they smoked 
$(n=474), 35.9 \%$ had not smoked anything the week before the survey, $16.8 \%$ had smoked 1 cigarette, and 20.1\% had smoked 10 or fewer cigarettes in the previous week [14]. In a study of University of Cairo students, $28.8 \%$ reported smoking less than once a day. The average age of initiation of smoking in that study was 19 years for males and 20 years for females [4].

\section{Education}

In addition to sex and age, factors such as level of education, characteristics of the educational environment and school performance have been associated with smoking behaviour. The DHS, SYPE and ASCE reported smoking status by level of education, but did not adjust for age, which is likely to be highly correlated with level of education among youth who may still be in school $[2,14,17]$. In the DHS sample of 1826 men aged 15-49 years, $58.3 \%$ of those with no education and $62.0 \%$ of those who had not completed primary school reported smoking, compared with $38.5 \%$ of men who had completed primary or secondary school [17]. A community-based survey of 1162 men and 958 women in Alexandria found that among males, current smokers tended to be less educated than never smokers, whereas the opposite was true for females: current smokers were better educated than never smokers, and of the 14 women in the study who were current smokers, 6 had a university degree [26].

A survey in rural Qualyobia secondary schools found that attending a maleonly school was a protective factor for smoking compared with attending a coeducational school ( $\mathrm{OR}=0.4,95 \%$ CI: $0.2-0.8$ ). The authors attribute this difference to boys thinking that smoking makes them look attractive to their female schoolmates [19]. In the study on University of Cairo students, smoking was less prevalent among those who had attended foreign language schools than among those who had attended Egyptian public or private schools or schools in other Arab countries. The author attributed this to greater health awareness among the higher socioeconomic groups in society, who can afford foreign language schools [4].

Although smoking is restricted on university campuses, enforcement may be lax and students may be unaware of these policies or reluctant to aid their enforcement by discouraging their peers' smoking. Allam interviewed a random sample of 108 male students at Cairo's Ain Shams University student unions, which ban smoking, and found that $27.8 \%$ of students thought that smoking was permitted in the unions. Researchers noticed a "low attitude regarding advising or asking friends or relatives to [extinguish] their cigarettes, not to smoke in his presence or to quit smoking" [27]. Students living in University of Alexandria hostels who smoked were more likely to have poor academic performance than good performance $\left(\chi^{2}=\right.$ $4.54, \mathrm{OR}=4.39)$ and the difference was statistically significant [24]. Students in the faculty of agriculture at Suez Canal University were found to be 2.7 times more likely to report smoking than were students at the faculty of medicine [22].

\section{Employment}

Smoking behaviour has also been related to youth employment. In an analysis of 4353 Egyptian boys aged 10-19 years in the ASCE data, those who did paid work were more likely to smoke than were those who did not work. For current paid workers, the likelihood of ever smoking was 1.71 times greater than those who had never worked, and for current smoking, the odds were 2.36 times greater for current paid workers compared with those who had never worked [28]. The authors note that, "assuming paid workers were more likely to work outside the home, they could have been exposed to a new network of smokers, people tolerant of smoking ... Paid adolescents may also have more disposable income for cigarettes." [28].
Similarly, among 687 students surveyed at Suez Canal University in Ismailia, current tobacco use was more prevalent among students with a higher monthly allowance (OR=3.4, 95\% CI: 2.2-5.2), and among working students $(\mathrm{OR}=$ 3.6, 95\% CI: 2.3-5.6) [22].

\section{Parents}

Both nationally and locally conducted research has examined the characteristics of parents and their association with youth smoking. An analysis of the 2001 GYTS of 3792 public school students aged 13-15 years across Egypt showed that more than half of current smokers were exposed to smoke from others in their household, whereas only about one third of never-smokers were exposed to smoke at home [20]. However, the Population Council's ASCE study of youth across Egypt found that parental smoking was not significantly correlated with adolescent smoking [14].

Islam and Johnson's 2003 survey of high-school students in Alexandria is one of the few studies that explicitly researched Egyptian youths' social norms and their smoking behaviour. The study identified a strong association between youth smoking and social norms established by siblings and household adults [11]. In a multivariate analysis adjusted for sex, age and socioeconomic status (SES), students whose siblings smoked were 3.5 times more likely to report ever-smoking (95\% CI: 2.3-5.2) and 3.9 times more likely to report having smoked within the previous 30 days (95\% CI: 2.6-6.1) compared with students whose siblings did not smoke. Those whose parents smoked were 2.3 times more likely to be ever-smokers (95\% CI: 1.6-3.2) and 2.1 times more likely to have smoked within the past 30 days (95\% CI: 1.4-3.1) in multivariate analysis. Perception of the proportion of adults who smoke was significantly associated with ever-smoking behaviour $(\mathrm{OR}=1.7,95 \% \mathrm{CI}: 1.6-1.9)$ and 30-day smoking behaviour $(\mathrm{OR}=1.2,95 \% \mathrm{CI}$ : 1.1-1.4) in multivariate analysis [11]. 
In a survey of 2000 students aged 12-18 years attending schools near Ain Shams University, 47.5\% reported that their father smoked, and $1.1 \%$ reported that their mother smoked, but the study did not report the correlation between parental smoking behaviour and respondents' smoking behaviour [21]. Among students interviewed in rural secondary schools in Qualyobia governorate, male students whose mothers had graduated from university were 3.7 times more likely to be current smokers than were the sons of illiterate mothers (95\% CI: $1-12$ ), which the authors attributed to less maternal supervision if the mother worked outside the home and to higher family income. About $62 \%$ of the students were exposed to smoke at home, and $55 \%$ of the students' fathers smoked; however neither parents' nor siblings' smoking status was found to be significantly related to male youth's smoking status. Citing earlier studies that did link parental smoking with youth smoking, the authors suggest that the high degree of exposure to smoking from all sources may conceal a link between parental and youth smoking [19]. In the same study, those males whose fathers had professional and semi-professional jobs were more likely to have ever smoked than were those whose fathers worked in skilled, semi-skilled or unskilled labour. Smoking also appeared to be more common among young men whose fathers were less educated, and these differences were statistically significant in bivariate analysis [19]. Nassar's study of University of Cairo students found that smoking was more prevalent among students whose parent was working or had worked abroad, which the author attributes to the higher economic status of the family allowing more disposable income for the respondent [4].

\section{Peers}

Research strongly and consistently links adolescent smoking in Egypt with smoking among their peers. Analysis of the 1997 ASCE data found that those who reported that their peers smoked were 7.99 times more likely to be current smokers (95\% CI: 4.82-13.23), and were 6.00 times as likely to have ever smoked (95\% CI: 4.49-8.04), in models adjusted for work status and education status [28]. Gadalla found that students who reported 1 or more peers as smokers were 3 times more likely to be smokers themselves (95\% CI: 2-5) [19].

Similarly, research on 302 14-18 year old students in Cairo, Giza and Qualyobia found that peer norms was one predictor of current smoking; others were perceived benefits of smoking and knowledge that smoking is addictive [23]. Islam and Johnson's survey of high-school students in Alexandria identified a strong association between smoking and social norms established by peers. Having peers who smoked increased the likelihood of ever-smoking by 2.1 (95\% CI: 1.4-2.9) and increased the likelihood of having smoked within the past 30 days by a factor of 2.6 (95\% CI: 1.4-4.6) in a multivariate analysis adjusted for sex, age and SES.

Perceptions of what proportion of their peers were smokers was also important: those who had a higher perceived peer norm for smoking were 1.3 times more likely to ever-smoke ( $95 \%$ CI: 1.2-1.4) and 1.3 times more likely to have smoked within the previous 30 days (95\% CI: 1.2-1.5) [11].

\section{Conclusions}

This review of the literature on youth smoking in Egypt has identified several characteristics that are consistently associated with smoking behaviour and that are related to youths' identity groups and social normative environments: male sex, older age and peers who smoke. Working has also been linked to a greater prevalence of smoking behaviour, and may be related to the social normative environment of the workplace. Several studies have looked at the relationship between living with smokers (parents or siblings) and smoking among youth, but the results are not consistent across studies.

This review of the literature has several limitations. The review was limited to materials published in English. It did not attempt to examine relationships between youths' SES and their smoking behaviour, although SES is often studied in relation to adult smoking behaviour and may relate to social norms. Some studies created social class indices. For example, Abolfotouh et al. created a 3-level SES status score based on education and occupation of parents, family size, housing conditions and family income [24]. Islam and Johnson created a wealth index based on 3 questions about parents' education levels and student's weekly spending money [11]. Other studies referred to characteristics related to class, such as parents' education $[19,22]$ and parents' work status $[4,19]$. Overall, however, the methodology was inconsistent across studies and a meaningful summary of social class and youth smoking was beyond the scope of this article.

\section{Suggestions for future research}

Several areas of further research could yield useful information about youth smoking and the normative environments that encourage or discourage youth smoking. Research on religion and religiosity with relation to smoking behaviour would be informative. Islamic religious scholars have found smoking to be either "completely prohibited or abhorrent to such a degree as to be prohibited" [29]. Among Ain Shams students, $80.6 \%$ reported knowing about the fatwa ruling on smoking [27]. Radwan et al. interviewed 322 youth aged less than 18 years in rural Qualyobia and found that $77.2 \%$ of 
males and $69.3 \%$ of females knew of the fatwa on smoking. Similarly, among 635 secondary school students $87.4 \%$ of males and $69.6 \%$ of females knew about the fatwa [30]. Future research should examine how Egyptian youths' participation in religious activities and their social groupings based on religion relate to their smoking behaviour.

One study suggested that smoking was less prevalent among students in male-only schools in Qualyobia, and another suggested that smoking was less prevalent among students from foreign language schools who matriculated to the University of Cairo [19]. Additional research or secondary analysis of existing data would be helpful in determining whether these trends hold true in other samples of Egyptian youth, and to try to explain what social normative mechanisms related to the school environment might influence youth smoking behaviour. Another study suggested that among women, those who smoke tend to be more educated than those who do not smoke [26]. It would be interesting to study social norms about cigarette smoking among female university students and university graduates. Research is also needed on out-of-school youth, particularly those who are not likely to be included in household surveys.

Several of the studies reviewed here used definitions of youth smoking that were the same or close to the GYTS definitions of never smoking (not even a puff or 2), ever smoking and current smoking (at least once in the previoous 30 days). Consistent terminology and use of validated survey items will help to ensure the comparability and generalizability of future research.

None of the studies reviewed here reported findings from longitudinal (panel) data, and few reported the results of multivariate analyses that were adjusted for known correlates. Future research should use more powerful research designs and sophisticated analyses to generate specific and actionable research findings and make policy recommendations.
Egypt signed the WHO Framework Convention on Tobacco Control in 2003 and ratified the agreement in 2005 [31]. The Framework encourages tobacco prevention, cessation and research programmes among its signatories. Youth's social normative environments should be included in research agendas and in prevention and cessation programmes for youth in Egypt. Social norms powerfully influence human behaviour [32] and offer a means to defend against tobacco marketing targeted at youth [5].

\section{Acknowledgements}

The author gratefully acknowledges the support of the Fulbright Bi-National Committee and thanks the Population Council Western Asia and North Africa Regional Office and the Center for Communication Programs at Johns Hopkins Bloomberg School of Public Health for providing office space and encouragement during the preparation of this article.

\section{References}

1. Assaad R, Roudi-Fahimi F. Youth in the Middle East and North Africa: Demographic opportunity or challenge? Washington DC, Population Reference Bureau, 2007.

2. Survey of young people in Egypt: Preliminary report February 2010. Cairo, Population Council, 2010 (http://www. popcouncil.org/projects/SYPE/index.asp, accessed 11 April 2011).

3. Corrao MA et al., eds. Tobacco Control Country Profiles: Economics of tobacco in Egypt. Atlanta, Georgia, America Cancer Society, 2000.

4. Nassar H. The economics of tobacco in Egypt: a new analysis of demand. Health, Nutrition and Population Discussion Paper. Washington DC, World Bank, 2003 (Economics of Tobacco Control Paper No. 8).

5. The tobacco industry's tactics and plans to undermine control efforts in Egypt and North Africa. Cairo, World Health Organization Regional Office for the Eastern Mediterranean, 2003 (WHO-EM/TFI/012/E/G).

6. Rimal RN, Real K. Understanding the influence of perceived norms on behaviors. Communication Theory, 2003, 13(2):184203.

7. Ajzen I, Fishbein M. Understanding attitudes and predicting social behavior. Englewood Cliffs, New Jersey, Prentice Hall, 1980.

8. Bandura A. Self-efficacy: the exercise of control. New York, W.H. Freeman, 1997.
9. US National Library of Medicine, National Institutes of Health. [website].(http://www.ncbi.nlm.nih.gov/pubmed/, accessed 23 January 2011).

10. PsycINFO. American Psychological Association [website] (http://www.apa.org/pubs/databases/psycinfo/index.aspx, accessed 23 January 2011).

11. Islam SM, Johnson CA. Influence of known psychosocial smoking risk factors on Egyptian adolescents' cigarette smoking behavior. Health Promotion International, 2005, 20:135-145.

12. Islam SMS, Johnson CA. Western media's influence on Egyptian adolescents' smoking behavior: the mediating role of positive beliefs about smoking. Nicotine \& Tobacco Research, 2007, 9:57-64.

13. Fact sheet: Eastern Mediterranean Region. Global Youth Tobacco Survey (GYTS) Egypt. Centers for Disease Control and Prevention [website] (http://www.cdc.gov/tobacco/global/GYTS/ factsheets/emr/2005/Egypt_factsheet.htm, accessed 23 January 2011).

14. Transitions to adulthood: a national survey of Egyptian adolescents. Cairo, Population Council, 2000.

15. El-Zanaty F, Way A. Egypt demographic and health survey 2000. Calverton, Maryland, ORC Macro/Cairo, Ministry of Health and Population and National Population Council, 2001.

16. El-Zanaty F, Way A. Egypt demographic and health survey 2005. Calverton, Maryland, ORC Macro/Cairo, Ministry of Health and Population and National Population Council, 2006. 
17. El-Zanaty F, Way A. Egypt demographic and health survey 2008. Calverton, Maryland, Macro International and Cairo, Ministry of Health and El-Zanaty and Associates, 2009.

18. Youssef RM, Abou-Khatwa SA, Fouad HM. Prevalence of smoking and age of initiation in Alexandria, Egypt. Eastern Mediterranean Health Journal, 2002, 8 (4/5):626-637.

19. Gadalla $S$ et al. Prevalence of smoking among rural secondary school students in Qualyobia governorate. Journal of the Egyptian Society of Parasitology, 2003, 33(Suppl.):1031-1050.

20. Dous NM. Report on the results of the Global Youth Tobacco Survey in Egypt. National comprehensive tobacco control program. Egypt, Ministry of Health and Population, 2003.

21. Aboul-Fotouh A et al. University advocacy on tobacco prevention in Egypt: partnership between Ain Shams University and the Egyptian Smoking Prevention Research Institute (ESPRI). Journal of the Egyptian Society of Parasitology, 2003, 33(Suppl.):1103-1110.

22. Refaat A. Practice and awareness of health risk behaviour among Egyptian university students. Eastern Mediterranean Health Journal, 2004, 10:72-81.

23. Ahmed O Jr et al. Tobacco education in Cairo, Egypt: is there an effect on adolescent smoking? Tobacco Control, 1999, 8:440-441

24. Abolfotouh MA et al. Health-related lifestyles and risk behaviours among students living in Alexandria University Hostels. Eastern Mediterranean Health Journal, 2007, 13:376-391.

25. Boulos DN et al. Nondaily, light daily, and moderate-to-heavy cigarette smokers in a rural area of Egypt: a population-based survey. Nicotine \& Tobacco Research, 2009, 11:134-138.
26. Youssef RM, Abou-Khatwa SA, Fouad HM. Current and never smokers: differentials in characteristics, knowledge and perceptions. Eastern Mediterranean Health Journal, 2003, 9:923-934.

27. Allam MF, Abd Elaziz KM. Role of members of university students' unions in tobacco prevention. Journal of Preventive Medicine and Hygiene, 2007, 48:136-140.

28. Sitrin D, Bishai D. The association between cigarette smoking and work status among Egyptian adolescent males. International Journal of Tuberculosis and Lung Disease, 2008, 12(6):670-676.

29. Khayat MH. Islamic rulings on smoking. Health education through religion series. The right path to health. Alexandria, World Health Organization Regional Office for the Eastern Mediterranean, 2000

30. Radwan GN et al. Impact of religious rulings (fatwa) on smoking. Journal of the Egyptian Society of Parasitology, 2003, 33(Suppl.):1087-1101.

31. El-Bakry R. New legislation aims to snuff out smoking. Business Monthly, Cairo, American Chamber of Commerce in Egypt, 2007 (http://www.amcham.org.eg/resources_publications/publications/business_monthly/issue.asp?sec $=4 \& \mathrm{im}=8$ $\&$ iy $=2007 \&$ subsec=New\%20Legislation\%20Aims\%20To\%20 Snuff\%20Out\%20Smoking Accessed 14 April 2011).

32. Yanovitzky I, Rimal RN. Communication and normative influence: An introduction to the special issue. Communication Theory, 2006, 16:1-6.

\section{Weekly Iron-Folic Acid Supplementation (WIFS) in women of reproductive age: its role in promoting optimal maternal and child health (WHO/NMH/NHD/MNM/09.2)}

These guidelines are based on the consensus of a World Health Organization (WHO) Global Consultation on Weekly Iron and Folic Acid Supplementation (WIFS) for Preventing Anaemia in Women of Reproductive Age held in Manila, Philippines, 25-27 April 2007 and summarizes recommendations based on a desk review commissioned by the WHO Regional Office for the Western Pacific (WPRO) and additional evidence presented and discussed in the expert consultation. It is intended for a wide audience including program implementing partners, scientists and governments involved in the design and implementation of micronutrient programs as public health interventions.

The guidelines are published in six langrages, including English and Arabic; they can be accessed at: http://www.unaids.org/documents/20101123_GlobalReport_em.pdf 